\title{
El álbum familiar de Mario Conde: transnacionalismo y memoria en Las cuatro estaciones de Leonardo Padura
}

Recibido: marzo 31 de 2016 | Aceptado: febrero 23 de 2018

DOI: 10.17230/co-herencia.15.29.12

\section{Jesús Gómez-de-Tejada* \\ manuel.gomezdetejada@uautonoma.cl}

Resumen La narrativa neopolicial del cubano Leonardo Padura Fuentes diluye los límites genéricos a través de la focalización de lo social por encima del proceso detectivesco. Los crímenes investigados por el teniente de policía Mario Conde en la tetralogía Las cuatro estaciones recrean la Cuba de 1989. A través del enfoque de la migración transnacional y la metodología propia del ámbito de la memoria en su trabajo con fotografías, este artículo analiza el álbum familiar del protagonista como dispositivo literario ligado a la nostalgia. Mediante este recurso, Padura refuerza la representación del peculiar transnacionalismo de Cuba, rasgo fundamental de su realidad, principalmente, a partir del Periodo Especial iniciado en los primeros años de los 90.

\section{Palabras clave:}

El neopolicial de Leonardo Padura Fuentes, memoria y álbum familiar, transnacionalismo.

\section{Mario Conde's family album: transnationalism and memory in Las cuatro estaciones by Leonardo Padura}

\begin{abstract}
The neo-detective narrative by Cuban author Leonardo Padura Fuentes dilutes genre boundaries by focusing on the social element rather than on the detective process. The crimes investigated by police lieutenant Mario Conde in the tetralogy Las cuatro estaciones (the four seasons) recreate the 1989 Cuba. Through both the transnational migration approach and the characteristic methodology of the field of memory in his work with photographs, this paper analyzes the family album of the protagonist as a literary device linked to nostalgia. By using this resource, Padura intensifies the representation of the peculiar Cuban transnationalism, a paramount feature of its reality, mainly since the Special Period which started in the early 90 s.
\end{abstract}

\section{Keywords:}

Leonardo Padura's neo-detective, memory and family album, transnationalism.
Este trabajo se enmarca en el Proyecto FONDECYT de iniciación 2017 N. 11171169 (CONICYT, Chile), que lleva por título "Calibre corto: sendas del cuento policial cubano", del que soy investigador responsable.

** Doctor por la Universidad de Sevilla, (España). Docente e Investigador, IDESH. Universidad Autónoma de Chile, Santiago, Chile. ORCID ID: 0000-0002-69400219. 
El neopolicial hispanoamericano se define como una narrativa criminal que utiliza el personaje detectivesco y la investigación del delito como una excusa para ofrecer una perspectiva crítica de la situación del país. ${ }^{1}$ En el caso cubano, las circunstancias singulares de su desarrollo histórico y político han gestionado un devenir específico de la escritura policial (Braham, 2004, p. 21; Wilkinson, 2006, p. 25). En este artículo se analizan las claves que permiten hablar de la novela neopolicial de Leonardo Padura Fuentes como un conjunto de textos que refleja el desarrollo del carácter transnacional de la contemporaneidad cubana. La resolución de los asesinatos gracias a las habilidades premonitorias e intuitivas del teniente investigador Mario Conde ofrece al lector un recorrido por una realidad habanera envuelta en la carestía, la corrupción, la persecución del tráfico de dólares y las salidas ilegales del país, que comienza a dibujar el panorama de una sociedad sustentada por las remesas procedentes del exterior gracias a la flexibilización de sus relaciones con la diáspora. Entre los vínculos económicos, políticos, familiares, culturales e ideológicos que se establecen entre los cubanos de dentro y fuera de la isla, la memoria y la nostalgia se constituyen en piezas claves de la perspectiva transnacional con que Padura construye su visión de La Habana de 1989. En este estudio, tales elementos son circunscritos al círculo más íntimo del protagonista a través de las fotografías de su álbum familiar. Las imágenes convertidas en prosa por el afán recordador del policía funcionan como dispositivos memorísticos impregnados de sentimientos de pérdida.

\section{El neopolicial de Padura}

Los cuatro títulos que dan inicio a las andanzas de Mario Conde son conocidos con la denominación de Las cuatro estaciones: Pasado perfecto (1991), Vientos de Cuaresma (1994), Máscaras (1997) y Paisaje de otoño (1998). El conjunto completo de las novelas se desarrolla en el año 1989, durante el invierno, la primavera, el verano y el otoño,

1 En palabras de Paco Ignacio Taibo II, igual que la Francia del siglo XIX está insuperablemente retratada en las novelas de Balzac, la mejor radiografía y el más exacto dibujo de la sociedad de los países hispanoamericanos no se hallan en los libros de historia ni en los periódicos, sino en las novelas neopoliciales (Valle, 2006, p. 194). 
respectivamente. Cada libro y cada estación dan pie a la narración de un caso policial, al mismo tiempo que el lector accede a las vivencias personales que marcan el trigésimo quinto año de la existencia de Conde. A causa de su constante tendencia a recordar, el tiempo real se confunde con el tiempo subjetivo del protagonista, hasta el punto que se hace patente que las cuatro estaciones telúricas se difuminan en una estación hecha de desencanto y nostalgia: la de la memoria.

La primera de las novelas, Pasado perfecto, se inicia con Conde sepultado bajo los efectos de una tremenda resaca matutina y la llamada telefónica de su jefe, el mayor Rangel, que lo pone en marcha hacia un nuevo caso. La cuarta y última entrega de la tetralogía, Paisaje de otoño, concluye con el cumpleaños de Conde tras su renuncia como policía. La serie tiene su continuidad en otras cuatro novelas que, salvo La cola de la serpiente (2011 [2001]) -igualmente ambientada en 1989, pero considerada fuera del primer conjunto-, se sitúan en años diferentes: Adiós, Hemingway (2014b [2001]), se ambienta ocho años después, en 1997; mientras que el siglo XXI acoge las peripecias del personaje en La neblina del ayer (2005) y Herejes (2013). En estas tres últimas, el lector se encuentra con el protagonista reconvertido en buscador y vendedor de libros de segunda mano, socio de un joven llamado Yoyi el Palomo, que aparece como representante de una nueva generación y una nueva Habana que él no acaba de comprender. En La neblina del ayer, el hallazgo de una fabulosa biblioteca hace de esta actividad una promisoria labor -que le permite vivir del invento, como a muchos cubanos durante el Periodo Especial. Sin embargo, en Herejes esta actividad pierde cualquier atisbo de seguridad. En 2007, año en que se sitúa la última novela de la serie, es un hombre arruinado y sin un claro horizonte profesional.

La trascendencia de la narrativa policial de Padura es incuestionable. El autor incursiona en el género para subvertir radicalmente la estética del realismo socialista de propósito panfletario y universo maniqueo del modelo anterior, que se había desarrollado con los auspicios del Ministerio del Interior (MININT). En 1972 y con carácter anual, este organismo creó el Concurso Aniversario del Triunfo de la Revolución para la narrativa policiaca, que posibilitó el auge cuantitativo de esta literatura durante los años 70 y buena parte de 
los 80. No obstante, según unánimemente ha proclamado la crítica, solo algunas obras alcanzaron niveles literarios aceptables, como por ejemplo El cuarto círculo (1976) de Luis Rogelio Nogueras y Guillermo Rodríguez Rivera, Joy (1977) de Daniel Chavarría, al igual que Y si muero mañana (1978) de Luis Rogelio Nogueras. La fórmula del policial revolucionario fue resumida en varias líneas por Nogueras y Rodríguez Rivera en la revista La Gaceta de Cuba (Rosell, 2000, pp. 448-449). Según ellos, el criminal es enemigo del Estado y no de un ciudadano concreto; el protagonista no es un detective particular singularmente brillante, sino miembro de un equipo policial de eficacia y moral irreprochables; el pueblo, que admira a estos héroes, se convierte en indispensable colaborador, sobre todo, a través de los Comités de Defensa de la Revolución. Instauradas de modo rígido por el Estado, estas premisas generaron una producción esquemática y oficialista servilmente destinada a difundir una realidad ideal. Tal subordinación del género fue nombrada por José Antonio Portuondo como el teque, cubanismo con el que designa su intención apologética y propagandística (1973, p. 131). La acción subversiva de Padura es plenamente consciente y, sobre todo, se refleja en el estilo paródico y en la voluntad de crítica social. Sus cuestionamientos y reflexiones ensayísticos en torno a la situación del género se consolidan en el conjunto de ensayos recogidos en Modernidad, posmodernidad y novela policial (2000), donde se destaca el capítulo, escrito en 1996, "Modernidad y posmodernidad: la novela policiaca en Iberoamérica", que incluye el análisis del caso cubano.

Las peripecias detectivescas de Conde van a servir de cauce para desvelar una realidad que el propio Padura caracteriza por el pesimismo y el desencanto, es decir, la pérdida de fe revolucionaria. Para él, las claves del neopolicial cubano, previamente iniciado en otros países hispanoamericanos como México, son las siguientes: menor importancia del enigma dentro de la narración, inclusión de elementos de la cultura popular, uso de un lenguaje contextualizado y cotidiano, sustitución de protagonistas pulcramente heroicos por individuos con mayores matices y, en general, marcados por la frustración y golpeados por la vida (Rosell, 2000, p. 451).

La reformulación quizás más significativa afecta al protagonista (Michelena, 2006, p. 45). De modo recurrente, el personaje es 
descrito por otras voces de la diégesis y por sí mismo. Dichos retratos y autorretratos nos ofrecen una imagen profunda de su aspecto y personalidad. Frente al carácter intachable, inmaculado, integrado y cooperativo definido por el arquetipo policiaco revolucionario, Conde, a pesar de su eficacia, resulta lo opuesto: solitario, neurótico, alcohólico y desaliñado. Metadiegéticamente, el propio Padura ha revelado su concepción trascendente del personaje y de estas novelas policiales. Según el autor, Conde es una metáfora (Uxó, 2006, p. 32). Desencantado, sin vocación policial, deseoso -y temeroso- de ser escritor, amante del béisbol, extremadamente comprometido en la fidelidad de sus lazos de amistad, atado a Cuba -o mejor, a su barrio, donde nació, creció y vive- por un irrompible nudo de pertenencia, el protagonista se convierte en el retrato de una llamada generación escondida. El grupo de personas que la constituye queda caracterizado por Padura -autoincluido en ella- como seres que creyeron y no obtuvieron nada a cambio, que obedecieron en pos de un ideal que se disipó con el tiempo, que nunca tuvieron libertad para hacer su voluntad y acabaron envueltos en el deterioro físico y espiritual, alejados de los arquetipos fijados como meta por las consignas socialistas (CasamayorCisneros, 2013, p. 122). Esta metáfora y este esbozo generacional comienzan con la elección del año en que transcurren los sucesos de las cuatro novelas. En palabras del novelista, 1989 es percibido como el año del cambio; como un momento de confluencia de hitos negativos que provoca la pérdida general de la fe en el proyecto revolucionario, el desmoronamiento definitivo del sueño socialista en el imaginario popular (Uxó, 2006, p. 71).

Padura ha señalado que sus novelas tratan de mostrar el desencanto de una generación ante la situación de arribismo, corrupción, narcotráfico, violencia y prostitución que había acabado emergiendo desmedidamente tras lustros de proceso revolucionario. Para denunciar estos hechos, el autor crea su propia fórmula caracterizada por la presencia de:

[un] enigma, que sólo sirve como pretexto para [...] una crítica severa de los errores de la revolución; un criminal que siempre resulta ser un delincuente disfrazado de hombre respetable e integrado al proceso revolucionario; un investigador que no puede resolver el conflicto más grande, el de su propia vida, y una sociedad, que lejos de cooperar con 
las fuerzas de investigación se mantiene ajena y envuelta en su propia tragedia (Rosell, 2000, p. 452).

Este énfasis sobre el predominio de lo social en las novelas no ha subrayado, sin embargo, los recursos narrativos mediante los que se configuran los lineamientos de un concepto transnacional del país. ${ }^{2}$

\section{El transnacionalismo cubano en Las cuatro estaciones}

El presente cubano está registrando cambios determinantes en las políticas migratorias desde octubre de 2012 hasta nuestros días. A ellos se agregan los recientes hitos en el rediseño de las relaciones bilaterales entre Cuba y Estados Unidos. Las repercusiones de ambos procesos, aún en desarrollo, han modificado significativamente los flujos y circunstancias de entrada y salida de la isla de los cubanos emigrados y de los ciudadanos cubanos residentes y no residentes en el país. ${ }^{3}$ Sin embargo, el periodo temporal en que se desarrolla la serie de Conde presenta condicionamientos legales y simbólicos concretos que difieren de la situación actual.

Weymer expresa que "el discurso cubano relativo a la gente que sale de la isla se ha formulado y reformulado a lo largo de cinco décadas"; las tensiones y vaivenes entre las políticas migratorias de Cuba y Estados Unidos exigen focalizar los cambios en las posturas de ambos países, puesto que de ellas se deriva la variabilidad de vivencias de una diáspora de naturaleza cambiante (Weymer, 2008, p. 28). Eckstein señala que, a partir de 1959, las relaciones institucionales e informales entre la isla y su diáspora pueden dividirse en dos periodos separados por las circunstancias creadas a partir del Periodo Especial. Después de 1989, según la autora, hay un

2 Esta visión transnacional se refuerza con la atención dedicada a las comunidades chinocubana y judeo-cubana en La cola de la serpiente y Herejes, respectivamente.

3 Krull resume las modificaciones reguladoras incluidas en el Decreto-Ley N. 302 del 16 de octubre de 2012, que comenzó a aplicarse el 14 de enero de 2013. Para dejar Cuba, los residentes cubanos ya no necesitan ni el permiso de salida ni la carta de invitación del lugar de destino. Los cubanos pueden viajar, trabajar fuera y volver cuando quieran (Krull, 2014, p. 3). Se abre la posibilidad de un régimen circular, que ha llegado a materializarse en una migración temporaria hacia Miami que forma parte del soporte financiero de los cubanos de hoy en día (Viera, 2015, s. p.). No obstante lo señalado por Krull, el Decreto-Ley aún fija restricciones a la libertad de entrada y salida. 
debilitamiento de las barreras oficiales y oficiosas para el flujo de actividades transnacionales, especialmente promovido desde Cuba, que enfrentaba una crisis sin precedente (Eckstein, 2014, pp. 288, 291-292). ${ }^{4}$

Los márgenes cronológicos del tiempo de la historia desarrollada en Las cuatro estaciones se sitúan en 1989, aunque hay que tener en cuenta los movimientos narrativos analépticos que trasladan al lector a décadas anteriores. La continuación de la serie prolonga los límites temporales hasta 2007. El año en que transcurre la tetralogía estacionaria funciona como bisagra entre dos posicionamientos del Gobierno revolucionario: una estrategia de condena y crítica hacia la diáspora, y otra de promoción y fortalecimiento de los vínculos con los cubanos de fuera. La crisis económica convirtió a los migrantes en posible fuente de recursos para compensar las urgentes necesidades materiales. Los cambios en las políticas económicas y migratorias se dirigieron desde entonces a atraer las remesas en dólares que de forma creciente llegaron desde el exterior (Eckstein, 2014, pp. 287-288).

El transnacionalismo -que, como enfoque en los estudios migratorios, surgió hacia los años 90 - se define en virtud de las relaciones que los sujetos (trans)migrantes y los residentes en el lugar de origen mantienen entre sí a nivel institucional, organizacional o particular (Glick, Basch \& Black-Szanton, 1992, p. 1). La prolongada excepcionalidad del transnacionalismo cubano no ha impedido la conformación de una red a través de la cual las fronteras se difuminan en virtud de los viajes, intercomunicaciones y remesas que se generan en su interior (Duany, 2011, pp. 20-21). ${ }^{5}$

4 No obstante, el informe titulado La diáspora cubana del siglo XxI (2011), siguiendo la terminología propuesta por Peggy Levitt y Nina Glick Schiller, define al Gobierno cubano como un "Estado desinteresado y denunciante" en relación con su diáspora, caracterizado por la falta de reconocimiento de la doble ciudadanía, la negación del derecho al voto externo, la imposibilidad de presentarse como candidato en la elección de cargos públicos, la migración de una sola dirección y los vínculos trasnacionales limitados y no institucionales (Cuban Research Institute, 2011, p. 19). Este carácter determina el excepcionalismo transnacional cubano en el ámbito caribeño (Duany, 2011, pp. 138-140).

5 En su estudio del transnacionalismo caribeño, frente a concepciones más amplias o más restringidas, Duany defiende una concepción intermedia donde las actividades transnacionales -viajes, comunicaciones y remesas- pueden estar patrocinadas o no por el Estado, y ser recurrentes u ocasionales (Duany, 2011, pp. 20-21). 
Igual que otros aspectos de la sociedad cubana, la migración y los flujos transnacionales son enfocados con diferentes grados de intensidad y modos de aparición en Las cuatro estaciones. Cada una de estas posibilidades permite reflejar aspectos de la política migratoria y su evolución durante el Gobierno revolucionario, así como vínculos entre el interior y el exterior de la isla: oleadas migratorias sucesivas, huida ilegal, permisos de salida y entrada, salida definitiva, consideración simbólica de los migrantes, remesas, regalos, visitas, contactos.

En primer lugar, dichos elementos se presentan por medio de simples alusiones de carácter general referidas a la población en su conjunto o de naturaleza más específica a través de individuos con nombre propio. En este rango, aparecen recurrentemente las remesas de cigarros que el mayor Rangel recibe del exterior a través de su hija casada con un extranjero y que suponen ya un cierto gusto por el materialismo que se va abriendo paso entre los principios de austeridad socialista (Eckstein, 2014, pp. 293-294). En Paisaje de otoño, el relato de Gloria, la mujer del antiguo cuadro del gobierno Miguel Forcade Mier, se convierte en una ventana a las salidas y a las visitas permitidas, excepcionalmente, por los gobiernos de ambos lados del estrecho de Florida. Dicho personaje muestra la reconfiguración del imaginario de los cubanos de la isla respecto a la diáspora, promovida por el desengaño ideológico, la necesidad material y el cambio de retórica oficial al dirigirse a ella como la comunidad de cubanos en el exterior (antes llamados contrarrevolucionarios, burguesía, traidores, escoria o gusanos). A través de la vuelta a Cuba de Gloria, además de ofrecer una visión desoladora de Miami, se alude al cambio en la percepción social y simbólica de los emigrados: "la familia [...], cuando me fui para Miami, por poco hasta me excomulgan [...] Pero como ahora vine con dólares, no saben en qué altar me van a poner [...] Todo por unos jeans, unas camisetas con un letrero y un par de ventiladores chinos" (Padura, 2014a, p. 71). En Vientos de Cuaresma, el viejo vecino de la víctima comenta confidencialmente a Conde su animadversión hacia ella por haberle increpado que "lo que tenía que hacer era irme de aquí con mis hijos gusanos, que era un padre de gusanos" (Padura, 2007, p. 176); enfrentamiento que, de nuevo, apunta al desprecio que, hacia los emigrados, sentían los cubanos 
que permanecieron en la isla y que funciona como barrera informal hasta 1989 (Eckstein, 2014, pp. 289-290). En Máscaras, la memoria y el caso del travesti asesinado conducen a Conde a recordar a un antiguo coetáneo del barrio de La Víbora, estigmatizado desde niño por sus preferencias sexuales y que "[e]n 1980, gracias a su indiscutible condición de homosexual y, por tanto, de escoria, antisocial y excluible, se le permitió abordar tranquilamente una lancha en el puerto del Mariel y salir hacia Estados Unidos" (Padura, 2012, p. 76).

En segundo lugar, el enfoque del transnacionalismo se realiza gracias al tratamiento secuenciado de diversos personajes y sus circunstancias a lo largo de la tetralogía. Especialmente reseñables son los casos de Andrés y Dulcita, miembros del círculo íntimo de Conde, que al mismo tiempo pueden verse como casos diferenciados. Dulcita y su salida de la isla a fines de los años 70 son aludidas puntualmente a través de los recuerdos de Conde. Su personaje subraya el tratamiento gubernamental y social recibido por los cubanos que abandonaron su tierra. En Pasado perfecto, el adiós de Dulcita tiñe su imagen de interrogación, silencio y olvido: "[e]ntonces, Dulcita era perfecta [...], y nunca entendí por qué se fue para los Estados Unidos, cuando me lo dijeron no lo creí, si era igual que todos nosotros, qué habrá sido de su vida..." (Padura, 2013a, p. 93). La retórica revolucionaria, promovida por los discursos de Fidel Castro, asoció salir de Cuba con la deserción y la traición: el heró́smo consistía en quedarse al lado del pueblo presto a la lucha, la solidaridad y el sacrificio; por el contrario, marcharse a Estados Unidos suponía traicionar el ideal y servir al imperialismo (Eckstein, 2014, p. 288). La incapacidad de comprender de Conde va unida a la clandestinidad de Dulcita, que se marcha secretamente y solo realiza una llamada a Carlos el Flaco. La bondad y el compromiso ejemplares de la joven imposibilitan al policía justificar su salida como un caso de disidencia política; la persistente incógnita creada por las posibles razones de la amiga se inunda de ese cansancio histórico que le irá abrumando con el paso de los años. La voz interior del protagonista recoge el carácter definitivo que tuvo durante décadas salir del país y la presión oficialista que forzaba a romper lazos familiares, afectivos y sociales con los que renunciaban a su deber con la Revolución y emigraban, como se advierte en este pasaje de Vientos de Cuaresma: 
Dulcita que se va. [...] se va es irse, pirarse, partir raudo y veloz, ir echando, con un solo destino: Miami. Se va es no volver.

[...] Dulcita era la mejor de todos nosotros [...]. Tal vez nunca la volveríamos a ver. [...], ni le podríamos escribir, ni le podríamos hablar, casi ni la podríamos recordar, porque se va y el que se va está condenado a perderlo todo, hasta el espacio que ocupa en la memoria de los amigos. ¿Pero por qué se va? (Padura, 2007, pp. 50-51)

Dulcita canaliza las alusiones a las visitas de cubanos emigrados a la isla. En Máscaras, anuncia a Carlos el Flaco su vuelta para visitar a un familiar enfermo. En los títulos posteriores a la tetralogía, las remesas y las visitas vinculadas a ella adquieren periodicidad. A través de este personaje se refleja el fortalecimiento de los vínculos transnacionales entre los emigrados y sus allegados en Cuba, no solo entre los que habían salido recientemente del país, sino también entre aquellos que lo habían abandonado con anterioridad a 1989, y que por razones humanitarias dejaron a un lado los prejuicios políticos o ideológicos que los distanciaron de los suyos (Blue, 2005, p. 38).

Distintos matices caracterizan la salida de Andrés, que se produce en Paisaje de otoño como cierre de la tetralogía y que en el resto de títulos funciona como paradigma transnacional. Su marcha es anunciada a sus amigos durante uno de los rituales en torno a la mesa prodigiosa de Josefina, madre de Carlos el Flaco. ${ }^{6}$ El episodio alude también a la notificación a sus superiores de su deseo de salir y a la represalia que ello pudiera acarrearle en los ámbitos laboral y vecinal, puesto que tal decisión supuso la pérdida del trabajo y el ostracismo social durante décadas (Duany, 2011, p. 139). El paso era obligatorio, puesto que para tramitar la salida legal del país había que aportar el informe del centro de trabajo junto al pasaporte corriente, el permiso de salida y la carta de reclamación del país de destino, según lo estipulado en el reglamento de la Ley de Migración cubana de 1976. Su confesión, que desgrana cómo ha ido recabando todos los documentos necesarios, se estructura sobre el concepto de generación escondida y sobre su relación con el padre que abandonó a su familia veintiséis años antes, "cuando más falta

6 Desde la gastrocrítica, Renée Clémentine Lucien describe la cocina de Josefina como el extremo de la abundancia y como un modo subversivo de enfrentar la austeridad vinculada a la Revolución socialista cubana (citado en Maeseneer, 2012, pp. 167-170). 
hacía que siguiéramos juntos, y dejó su país y se convirtió en un gusano despreciable, viviendo en Miami” (Padura, 2014a, p. 247). La relación paterno-filial ejemplifica la breve apertura que a fines de los años 70 el Gobierno revolucionario implementó hacia la comunidad cubana en el exterior. Paralelamente a la eliminación puntual de las designaciones negativas de la diáspora, se ejecutaron cambios en la política migratoria que permitieron las visitas a Cuba de manera temporal. Este breve periodo, que concluyó con los episodios de la embajada de Perú y del puerto de Mariel en 1980, supuso la base del incipiente transnacionalismo que se desarrolló durante 1981 y 1989, hasta que a partir de este último año, las condiciones creadas por la crisis permitieron el crecimiento continuado de las conexiones (Blue, 2005, p. 27). La carta enviada por el padre desde Miami al final de la década de los 70 supone el comienzo de la reconciliación entre ambos y establece los lazos necesarios para la salida de Andrés y su familia en 1990, según se cuenta en Adiós, Hemingway.

El informe La diáspora cubana del siglo XxI defiende que los vínculos transnacionales extraoficiales se proyectan como base del entendimiento y del diálogo necesario para el encuentro de todos los cubanos. Por ello, el documento preconiza que el futuro próximo de Cuba debe construirse sobre este fundamento (Cuban Research Institute, 2011, pp. 14-15). El amargo desencanto que destilan las novelas de Padura deja traslucir dicha esperanza. El tratamiento literario de la necesidad de normalización de esta vía transnacional alcanza su mayor simbolismo por medio del lanzamiento de un mensaje en una botella que Conde -ebrio de alcohol, amistad y nostalgia- lanza al mar desde el malecón de Cojímar en 1997 con destino a su amigo Andrés, emigrado a Estados Unidos siete años antes (Padura, 2014b, p. 187). En las últimas páginas de Adiós, Hemingway, Conde se hace eco del giro que, a fines del siglo XX, se produjo en la actitud y la retórica oficial que durante lustros condenó como antirrevolucionarios a los emigrados y los borró de la memoria de la nación. El mensaje en la botella, firmado por Conde, Carlos el Flaco y el Conejo, es una declaración de amistad que funciona como metafórica creación o confirmación de una red establecida entre ambos lados del estrecho de Florida. Por ello, la nota inserta en el vidrio solicita la contestación del amigo residente en Miami: 
"A Andrés, en algún lugar del norte: Cabrón, aquí nos estamos acordando de ti. Todavía te queremos y creo que te vamos a querer siempre [...], ojalá que allá tú nos sigas queriendo, porque hay cosas que no se pueden perder. [...] Hemos perdido casi todo, pero hay que salvar lo que queremos. [...] Cuando recibas este mensaje, devuelve la botella, pero llena". [...]

Entonces tomó impulso con el brazo hacia atrás y lanzó la botella al agua. El recipiente epistolar, preñado con las nostalgias de aquellos náufragos en tierra firme, quedó flotando cerca de la costa, brillando como un diamante invaluable, hasta que una ola lo envolvió y lo alejó hacia esa zona oscura donde sólo es posible ver algo con los ojos de la memoria y el deseo. (Padura, 2014b, pp. 188-190)

La escena pone el foco en los miembros de una generación de cubanos que se perciben como desafortunados supervivientes del hundimiento de un sueño en el que la historia los embarcó, como a integrantes del Estado revolucionario instituido desde 1959. El cansancio histórico de Conde guarda una nota de esperanza depositada en un espacio utópico donde el pasado (memoria) y el futuro (deseo) permitan el redescubrimiento del valor de un socialismo original, de una fraternidad incluyente estrechada en lazos cubanos transnacionales. ${ }^{7}$ Este gesto utópico se aparta parcialmente de las posiciones que Casamayor-Cisneros destaca en los narradores postsoviéticos de la literatura cubana insular, incluyendo al Padura de La novela de mi vida (2002). Tales posturas están caracterizadas por la recursividad de la visión asociada al cubano de dentro -orgulloso de su superioridad por resistir a las arremetidas de la Historia- respecto del cubano emigrado -estigmatizado por la inferioridad que le reporta el abandono de la isla (Casamayor-Cisneros, 2013, p. 172)-. Igualmente, aunque desde la orilla contraria, el pasaje citado invierte otros similares de la narrativa del exilio, donde el protagonista, guiado por la memoria o por la posmemoria (Hirsch, 1997, pp. 21-22), ${ }^{8}$ establece puentes simbólicos o reales con el lugar de origen. ${ }^{9}$ En las sucesivas entregas

7 Casamayor-Cisneros arguye que el cansancio histórico de los personajes es un modo de subsistencia que libra a los personajes de quedarse desprovistos de toda certeza (2013, p. 124).

8 Con el término posmemoria, Hirsch alude a la memoria de los hijos de los supervivientes del holocausto nazi.

9 Méndez, al referirse a lo distópico en la literatura de la diáspora cubana, comenta el 
de la serie, estas conexiones se manifiestan por medio de llamadas telefónicas, cartas, envío de medicamentos, regalos o contactos a través de terceros llegados a la isla.

\section{El álbum familiar de Mario Conde}

Desde el punto de vista de la memoria, el estudio de Las cuatro estaciones cobra pleno sentido gracias al carácter metaficcional que adquiere el texto a partir del segundo título, Viento de Cuaresma, cuando la tetralogía es presentada como resultado de la escritura catártica de Conde. Este recurso, algunos paratextos y diversos comentarios metatextuales de Padura tiñen la obra de rasgos autobiográficos que, sin negar la ficción, afectan tanto al autor como al protagonista. Más allá de similitudes anecdóticas entre uno y otro, la estructura del relato orienta hacia la interpretación de los cuatro títulos como la narración literaria, memorística y autobiográfica de un policía con pretensiones novelescas.

La vinculación entre la escritura y la memoria es explicitada en la concepción que el personaje principal tiene sobre el proceso de creación. En consonancia con Assmman y Shortt, que expresan la maleabilidad de la memoria y la necesidad de la representación del pasado para liberarlo de la virtualidad de esta $(2012$, p. 3), Conde la define como un "territorio libre" donde reelaborar el pasado como un tiempo similar a la felicidad (Padura, 2014b, p. 80). A modo de leitmotiv, el texto expresa las ansias de este por canalizar su pulsión artística a través de una historia escuálida y conmovedora -influencia de J. D. Salinger-, que no puede ser sino la de sus amigos, es decir, la de su generación. Conde cita a Hemingway para afirmar que un autor debe contar lo que conoce y reflexiona sobre la posibilidad de escribir una historia que se llame Pasado perfecto (Padura, 2007, p. 28). La tetralogía se cierra con el exteniente de policía volcado sobre su "vieja máquina Underwood", confiando su salvación y la de los suyos a la memoria que posibilita el "acto mágico de extraer aquella crónica de dolor y de amor" (Padura, 2014a, p. 259). De este modo, la serie se convierte en narración de la memoria colectiva,

desenlace de la novela The Marks of Birth (1994), de Pablo Medina, como ejemplo de representación simbólica de los vínculos entre ambos lados del estrecho de Florida (Méndez, 2007, p. 155). 
que representa el pasado compartido y conmemorado por el grupo, y que define su identidad en función de la realidad de su presente y su perspectiva de futuro (Misztal, 2003, p. 7).

Esta lectura autobiográfica y memorística, al igual que la construcción de la realidad transnacional cubana, se ve fortalecida por la inclusión de dos fotografías tomadas del álbum del teniente, del que no se especifica su realidad como objeto ni alusiva ni descriptivamente; tan solo se mencionan unas "fotos, confinadas como estigmas al cajón de las nostalgias malignas" (Padura, 2014a, p. 163). Dichas fotografías no son insertadas como imágenes, sino a través de pasajes metafotográficos, es decir, fragmentos narrativo-descriptivos focalizados en la contemplación de una o varias instantáneas. ${ }^{10}$ Este dispositivo, que intensifica el recuerdo y se sitúa "entre la memoria y el olvido" (Hirsch, 1997, p. 22, mi traducción), potencia la difuminación de los límites entre la historia y la ficción y relaciona las novelas con obras autobiográficas, testimoniales o de creación que introducen similares figuras. ${ }^{11}$ Además, su efecto se acrecienta porque las convenciones que rigen la realización de las instantáneas familiares generan un "espacio de identificación", que salva la distancia entre aquellos lectores partícipes del contexto histórico narrativo y aquellos alejados de él (Hirsch, 1997, p. 251).

Las fotografías muestran la imagen de dos grupos fundamentales de la existencia de Conde: el conjunto familiar y el círculo de amigos. Al reproducir las fases de la vida del ser humano y formar parte de un contexto social, las instantáneas se convierten en un producto cultural y son usadas comúnmente para fijar momentos importantes y de cambio, sobre todo en aquellos magnificados por la organización de reuniones celebratorias (Chalfen, 1987, pp. 74, 85). Por medio de las fotografías, especialmente al disponerlas en un álbum, las familias y los amigos crean una "crónica-retrato" de sí mismos (Sontag, 2006, p. 23). Si en Pasado perfecto se describe cómo Conde observa la instantánea que sus amigos y él se hicieron

10 Metafotografía y fotografía en prosa son términos utilizados por Hirsch para referirse al tratamiento textual (narrativo, descriptivo, emotivo y argumentativo) de una fotografía en un escrito más amplio: novela, autobiografía, memoria (1997, p. 8).

11 Dentro de la literatura cubana del exilio, Vista de amanecer en el trópico (1974), de Guillermo Cabrera Infante, destaca como pionera en el uso de esta fórmula narrativa (Alvarez Borland, 2009, p. 36). 
al terminar el preuniversitario en junio de 1975, en Paisaje de otoño se alude a las tomadas durante el octavo cumpleaños del protagonista celebrado el 9 de octubre de 1961. En este segundo caso, no se trata de la contemplación de las imágenes, sino de la nítida evocación de una de ellas. Ambas son escritas desde la nostalgia, entendida como "pérdida y desplazamiento" entre el pasado y el presente (Boym, 2001, pp. XIII-XIV, mi traducción).

El retrato colectivo de 1961 evocado a partir del recuerdo de la madre es, precisamente, un intento por eternizar, en toda su extensión generacional, la imagen familiar amenazada por la inminente muerte del anciano Rufino, abuelo de Conde, y por la reciente irrupción del Gobierno revolucionario. La imagen se convierte en rastro espectral de la familia dispersa y en el último resto conservado de ella (Sontag, 2006, p. 23). Como en otros ejemplos del libro, la unidad familiar se incorpora a las dinámicas de fragmentación, que durante décadas aislaron a los cubanos de dentro y fuera, y que actuaron como barreras informales contra las redes de intercambio transnacional:

En la última foto memorable de aquel cumpleaños memorable, el Conde recordaba uno por uno los familiares reunidos, todos sonrientes tras el cake con ocho velas, como si supieran que aquella conjunción de la tercera, la cuarta y la quinta generación de la familia de Teodoro Conde, el tránsfuga canario llegado a Cuba hacía siglo y medio, sería una imagen alarmante y final: la diáspora, la muerte, la distancia y la desmemoria acechaban a aquella familia. (Padura, 2014a, pp. 163-164)

La fotografía de junio de 1975, que reúne parcialmente al círculo de amigos de Conde (destaca la ausencia de Andrés), se corresponde con otro de los motivos comunes que conforman el álbum fotográfico estándar: el momento de la graduación (Chalfen, 1987, p. 85). En este caso, la instantánea conmemora el día de prematriculación en la universidad, justo antes de los exámenes finales del último curso en el instituto de La Víbora. Esta "última foto" en las escaleras del centro preuniversitario pone punto y final a una etapa de sus vidas (Padura, 2013a, p. 95). Con la entrada a la educación superior, los amigos pasan de la adolescencia a la juventud; en su caso, el tránsito se produce desde un periodo enmarcado por la felicidad, la unión y la fe en los principios de la Revolución a una etapa frustrada por el comienzo de la infelicidad, la separación y el desapego respecto de 
la realidad revolucionaria. La nostálgica mirada de Conde recoge la separación física y afectiva motivada por la salida de Dulcita. La joven, desde entonces interrogativamente estigmatizada como la que se fue, tendrá que esperar hasta la llegada del Periodo Especial para volver y restablecer las relaciones con sus viejos amigos como parte del proceso de fortalecimiento de las relaciones transnacionales.

Si se participa en el juego metanarrativo propuesto por Padura, desde el cual la lectura de la tetralogía es una escritura del propio Conde, esta prosa metafotográfica puede relacionarse con el taller autoetnográfico de fotografía y memoria, donde instantáneas y álbumes familiares se analizan desde una perspectiva social, genérica, cultural y personal. ${ }^{12}$ La escritura literaria de Conde-Padura desarrolla literariamente los cuatro pasos descritos por Kuhn como guía de estos talleres memorísticos: consideración del sujeto (a través de una simple descripción seguida de la narración de los sentimientos provocados por la contemplación), determinación del contexto, especificación de los elementos técnicos y estéticos, y aclaración de los detalles de autoría y recepción (Kuhn, 2007, pp. 284-285).

La reunión "del clan de los Condes" presenta, en primer término, el pastel conmemorativo y, justo detrás, a Conde con ocho años. Al lado del protagonista, se encuentra su madre, de la que recibe un beso. El abuelo Rufino descansa sobre una silla y sostiene sobre su regazo al futuro policía, que lo está abrazando. En el fondo y sonrientes, se encuentra el resto de parientes. La imagen mental es convocada por la excepcionalidad del gesto afectuoso de la madre (resalta la falta de alusión al padre). La descripción se entremezcla con la nostalgia sentida al recordar que "alguna vez había sido tan feliz y tan querido, tan miembro de ese concepto perdido llamado familia" (Padura, 2014a, p. 163). El trasfondo es el octavo cumpleaños de Conde, cuando se reunió, por última vez, todo el clan. La fecha de 1961 apunta al periodo inicial de la Revolución y la cohesión del grupo puede verse en paralelo con la esperanza traída con la expulsión de Fulgencio Batista. Las alusiones al extrañamiento familiar posterior, igualmente, se corresponden con el proceso diaspórico

12 Estos talleres consisten en sesiones de trabajo donde varios investigadores aportan sus propias fotografías familiares con objeto de describirlas e interpretarlas colectivamente dentro del ámbito de la etnografía y la memoria (Kuhn, 2007, p. 284). 
y el desencanto que, de un modo u otro, el devenir revolucionario fue creando. La imagen, especialmente evocada, forma parte de un conjunto de fotografías donde la familia posa ante un fotógrafo profesional contratado para la ocasión.

La instantánea dedicada a los amigos muestra a Carlos el Flaco, Dulcita, el Conejo, Tamara y el propio Conde de pie en "la escalinata del Pre". En el centro se sitúa el Flaco. A la izquierda de la foto, junto a él, Dulcita y, más allá, el Conejo. En la parte derecha, hacia el medio, está Tamara y, en el extremo, Conde. El texto se detiene con cierta minuciosidad en la apariencia física, las posturas, los gestos y la ropa de los sujetos de la imagen, que adquieren significado psicológico y simbólico. Los rostros sonrientes del Flaco, Dulcita y el Conejo contrastan con el rostro serio de Tamara y la risa torpemente forzada de Conde. Los brazos en cruz, la cabeza inclinada y la centralidad del Flaco se interpretan en paralelo con la figura de Cristo, augurio de su destino sobre una silla de ruedas, y con la fuerza cohesionadora ejercida sobre el grupo. La extrema delgadez de los sujetos masculinos y la pobreza de sus ropas apuntan a la escasez generalizada que caracterizó al Periodo Especial. El pelo largo del Flaco, la falda remangada de Dulcita y los pantalones de campana de Conde aluden al diversionismo perseguido por el discurso oficial y presagian el desencanto que se apoderará de ellos en la edad adulta. ${ }^{13}$ Del mismo modo, la mención del "escándalo Waterpre" actúa como antecedente de la corrupción institucional que comenzó a hacerse pública y recurrente a partir de 1989. Por último, la baja oferta de estudios literarios se correlaciona con la presión burocrática que la cultura sufrió durante el Quinquenio Gris (o la Década Negra, 1971-1976). El soporte físico de la imagen se comenta con algún detalle: una cartulina amarilleada por el tiempo y con una esquina estropeada por el agua de lluvia (Padura, 2013a, pp. 93-95).

La mirada de Conde es escrutadora; su contemplación morosa trata de ver "lo que hay detrás" (Barthes, 1989, pp. 151-153, cursivas en el original). Conde mira la foto intentando acceder a la verdad, a una

13 La retórica revolucionaria usó el término diversionismo para referirse a las actitudes que se confrontaban o se separaban del discurso oficial. Con él se aludía tanto a conductas y acciones culturales críticas como a comportamientos excéntricos desde el punto de vista social o sexual (cultura hippie y homosexualidad) (Gallardo-Saborido, 2009, pp. 218-223). 
explicación que no alcanza y que se traduce en desencanto hacia el presente y nostalgia por el pasado. Todos ellos posan en las escaleras para Rafael Morín, novio de Tamara, estudiante modelo, futuro cuadro del gobierno y muerto a consecuencia de su participación en un caso de corrupción. La identidad del fotógrafo justifica la mueca de Conde y la seriedad de Tamara en el presente detenido de la fotografía; así como el complejo de culpabilidad que el policía siente ante ella en 1989, "porque el Flaco ya no es flaco y porque detrás de la cámara, invisible pero presente ha estado siempre Rafael Morín” (Padura, 2013a, p. 95). La presencia ineludible de Morín como fotógrafo traza un paralelo entre la discusión de Derecho sobre si la posesión de la foto corresponde al autor o al sujeto de ella y la intromisión de los estados totalitarios en la vida de sus ciudadanos. El modelo es creado (y manipulado) por el operador; la fotografía convierte al individuo en objeto e información para fines burocráticos (Barthes, 1989, pp. 41-44, 60-61; Sontag, 2006, p. 40). Las lecturas son diferentes: Morín al capturar la imagen, de la que se autoexcluye, proyecta la acción manipulativa de su incipiente poder y, simbólicamente, registra los datos en el archivo oficial; Conde y sus amigos, a pesar de las imposiciones, posan para su álbum particular, ofreciendo una imagen concreta de sí mismos parcialmente opuesta a la norma (historia) gubernamental.

La posibilidad de identificar los pasos del método autoetnográfico con la prosa fotográfica del texto sistematiza la conceptualización de estos pasajes como dispositivos literarios que refuerzan su función memorística. La significación cultural de las fotografías y su papel como catalizadores de la memoria se mantienen en la contemplación y evocación solitarias de Conde. Ambos pasajes son memento mori. ${ }^{14}$ No solo la evocación de la imagen fija de la madre y el abuelo muertos, sino también la remembranza de sus otros familiares y la mirada absorta sobre el papel ajado donde aparecen eternizados sus amigos. Como "arte elegíaco" que prueba "la despiadada disolución del tiempo” (Sontag, 2006, p. 32), las fotografías visualizadas mental o físicamente ponen de manifiesto la destrucción de sus núcleos afectivos y, especialmente, el destino inextricable de su mejor amigo.

14 Para Sontag, "todas las fotografías son memento mori" (2006, p. 32). 
Lo que atrae la mirada o la mente de Conde hacia las fotografías, hasta atarlas entre sí "con una especie de cordón umbilical", es la conciencia desgarradora ("punctum") de "lo que ha sido"; el doloroso deleite de la nostalgia que le provoca su contemplación (Barthes, 1989, pp. 127, 146).

\section{Conclusión}

La innovación del género policial cubano realizada por Leonardo Padura Fuentes se basa en la parodia del modelo anterior a través de la presentación de un tipo de detective diferente, nuevos culpables y el predominio de lo social sobre la investigación criminal. En Las cuatro estaciones, entre los rasgos definidores de la realidad habanera, se hace notoria la alusión a una Cuba transnacional mediante el reflejo de los crecientes lazos entre la isla y su diáspora. Durante 1989, umbral del Periodo Especial, la nostalgia se adueña de cada uno de los pensamientos del protagonista a través del recuerdo doloroso de un pasado perfecto que rara vez lo fue. Para Conde, autor metaliterario de las novelas, la escritura como memoria es la única vía de salvación posible.

Al enfocar el análisis de Las cuatro estaciones desde la memoria, la elaboración literaria de los pasajes metafotográficos se aborda con mayor sistematicidad a partir del proceso de interpretación socio-cultural de instantáneas familiares implementado en talleres autoetnográficos. A partir de los pasos de este método, se comprueba cómo la inserción en el texto de dos fotos personales funciona como mecanismo retórico que intensifica el papel de la memoria y el sentimiento de pérdida, a la vez que alude a la creciente realidad transnacional de Cuba. Estas instantáneas son el punto de partida de la nostalgia que desborda a Conde, paradigma de una generación desencantada, a fines de los años 80 . Su mirada desengañada subraya el cansancio histórico del personaje y lo mantiene atado al presente congelado de las fotografías 


\section{Referencias}

Alvarez Borland, I. (2009). Figures of Identity: Ana Menéndez's and Guillermo Cabrera Infante's Photographs. En I. Alvarez Borland \& L. M. F. Bosch (Eds.), Cuban-American Literature and Art: Negotiating Identities (pp. 31-45). Albany: State University of New York Press.

Assmann, A. y Shortt, L. (Eds.) (2012). Memory and Political Change. Basingstoke: Palgrave Macmillan.

Barthes, R. (1989 [1980]). La cámara lúcida. Notas sobre la fotografía (J. Sala- Sanahuja, Trad.). Barcelona: Paidós.

Blue, S. A. (2005). From Exiles to Transnationals? Changing State Policy and the Emergence of Cuban Transnacionalism. In D. J. Fernández (Ed.), Cuba Transnational (pp. 24-41). Gainesville: University Press of Florida.

Boym, S. (2001). The Future of Nostalgia. New York: Basic Books.

Braham, P. (2004). Crimes against the State. Crimes against Persons. Detective Fiction in Cuba and Mexico. Minneapolis: University of Minnesota Press.

Casamayor-Cisneros, O. (2013). Utopía, distopía ingravidez: reconfiguraciones cosmológicas en la narrativa postsoviética cubana. España: Editorial Iberoamericana/Vervuert.

Chalfen, R. (1987). Snapshot Versions of Life. Bowling Green: Bowling Green State University Popular Press.

Cuban Research Institute, Florida International University. (2011). La diáspora cubana en el siglo XXI [en línea]. Recuperado de https://bit. ly/2y7YIOf

Duany, J. (2011). Blurred Borders: Transnational Migration between the Hispanic Caribbean and the United States. Chapel Hill: University of North Carolina.

Eckstein, S. (2014). Cuban without Borders. From the Buildup to the Breakdown of a Socially Constructed Wall across the Florida Straits. En C. Krull (Ed.), Cuba in a Global Context: International Relations, Internationalism, and Transnationalism (pp. 287-300). Gainesville: University Press of Florida.

Gallardo-Saborido, E. J. (2009). El martillo y el espejo: directrices de la política cultural cubana (1959-1976). Madrid: CSIC.

Glick Schiller, N., Basch, L. \& Blanc Szanton, C. (1992). Towards a Transnational Perspective on Migration. Race, Class, Ethnicity, and Nationalism Reconsidered. New York: New York Academy of Sciences. 
Hirsch, M. (1997). Family Frames: Photography, Narrative, and Postmemory. Cambridge: Harvard University Press.

Krull, C. (Ed.) (2014). Cuba in a Global Context. In C. Krull (Ed.), International Relations, Internationalism, and Transnationalism (pp. 1-26). Gainesville: University Press of Florida.

Kuhn, A. (2007). Photography and Cultural Memory: a Methodological Exploration. Visual Studies, 22(3), 283-292. Doi: https:/doi. org/10.1080/14725860701657175

Maeseneer, R. (2012). Devorando lo cubano. Una aproximación gastrocrítica a textos relacionados con el siglo XIX y el Período Especial. España: Editorial Iberoamericana/Vervuert.

Méndez Rodenas, A. (2007). Identity and Diaspora: Cuban Culture at the Crossroads. En A. O'Reilly Herrera (Ed.), Cuba: idea of a nation displaced (pp. 143-160). Albany: State University of New York Press.

Michelena, J. A. (2006). Aportes de Leonardo Padura a la literatura policial cubana. En C. Uxó (Ed.), The Detective Fiction of Leonardo Padura Fuentes (pp. 38-53). Manchester: Manchester Metropolitan University Press.

Misztal, B. A. (2003). Theories of Social Remembering. Maidenhead: Open University Press.

Padura Fuentes, L. (2000). Modernidad, posmodernidad y novela policial. La Habana: Ediciones Unión.

Padura Fuentes, L. (2007 [1994]). Vientos de Cuaresma (2.. ed.). Barcelona: Tusquets. (Colección Andanzas, 434)

Padura Fuentes, L. (2010 [2002]). La novela de mi vida (2. ed.). Barcelona: Tusquets. (Colección Andanzas / Serie Volumen independiente)

Padura Fuentes, L. (2011 [2001]). La cola de la serpiente. Barcelona: Tusquets. (Colección Andanzas, 690)

Padura Fuentes, L. (2012 [1997]). Máscaras. Barcelona: Tusquets. (Colección Maxi [Serie Mario Conde, 3])

Padura Fuentes, L. (2013a [1991]). Pasado perfecto (3. a ed.). Barcelona: Tusquets. (Colección Maxi [Serie Mario Conde 1])

Padura Fuentes, L. (2013b). Herejes. Barcelona: Tusquets. (Colección Andanzas, 813)

Padura Fuentes, L. (2014a [1998]). Paisaje de otoño (2. a ed.). Barcelona: Tusquets. (Colección Maxi [Serie Mario Conde 4])

Padura Fuentes, L. (2014b [2001]). Adiós, Hemingway (Colección Maxi [Serie Mario Conde 5]). Barcelona: Tusquets. 
Portuondo, J. A. (1973). Astrolabio. La Habana: Editorial de Arte y Literatura.

Rosell, S. (2000). La (re)formulación del policial cubano: la tetralogía de Leonardo Padura Fuentes. Hispanic Journal, 21(2), 447-458. Recuperado de https://bit.ly/2t2Xr4Q

Sontag, S. (2006 [1977]). Sobre la fotografía (A. Major, Trad.). México D.F.: Alfaguara.

Uxó, C. (Ed.) (2006). The Detective Fiction of Leonardo Padura Fuentes. Manchester: Manchester Metropolitan University Press.

Valle Ojeda, A. (2006). La nueva ciudad cubana (y/o La Habana otra) en la novelística negra de Leonardo Padura. En C. Uxó (Ed.), The Detective Fiction of Leonardo Padura Fuentes (pp. 192-199). Manchester: Manchester Metropolitan University Press.

Viera, F. L. (2015, agosto 24). "Por la izquierda" [en línea]. Cubaencuentro. Recuperado de https://bit.ly/2Mr8mya

Weymer, T. N. (2008). La diáspora cubana en México: terceros espacios y miradas excéntricas. New York: Peter Lang.

Wilkinson, S. (2006). Detective Fiction in Cuban Society and Culture. Oxford: Peter Lang. 